\title{
Singapore's Infocomm Drives E-Government Transformation
}

The Singapore public sector is committed to investing in infocomm to better meet the growing expectations of businesses and citizens. In May 2008 the Government announced plans to call for a Sing \$1 billion worth of new infocomm tenders for the financial year 2008. These included more than 390 new tenders covering a wide range of public sector projects such as the development of the second Government Data Center, enhancements to the Government's one-stop portal (www.gov.sg) a Command and Control System for the Singapore Civil Defense Force and an Identity Management Systems for the Ministry of Defense. The CEO of infocomm stated recently "We will continue to work with the industry to find new and innovative ways to use infocomm technology to improve our delivery of government services, strengthen our infrastructure as well as encourage citizen and businesses alike to adopt an infocomm enabled lifestyle."

Making IT SOEasy: A project when fully completed in 2010 will consolidate infocomm services into a single environment, allowing government agencies to achieve greater efficiency in infocomm usage. This involves harmonizing desktop, messaging and network environments across all government agencies - an exercise which will result in savings of Sing \$500 million for the Singapore Government.

In February 2008, the Sing \$ 1.3 billion SOEasy (Public Sector) tender was awarded to a consortium led by EDS International. Members of the consortium include Alcatel-Lucent, Avanade, Cisco Systems, Frontline, Microsoft, Singapore Computer Systems and Singtel. SOEasy is being implemented for a total of 24 government agencies, excluding the Ministry of Defense and the Ministry of Education. By July 2009, the first three government agencies - the Ministry of Finance, Ministry of Information, Communications and the Arts, and IDA will enjoy the full benefits of the consolidated infocomm platform.

In 2007, almost 9 our of $10(89 \%)$ who transacted with Government did so electronically - via the Internet, automated kiosks, e-mail, Interactive Voice Recognition System and Short Message Service (SMS). These users were typically young adults (aged 20 to 39 years old), and white-collar workers.

More than 8 out of $10(86 \%)$ gave a rating of 4 and above on a 6-point scale on their satisfaction with the quality of Government e-Services.

To address the needs of senior citizens and bluecollar workers $w$ ho are not as comfortable with interacting with Government agencies through electronic channels, 28 Citizen-Connect Centers have been set up to assist them. These centers offer free Internet connectivity for them $t$ access government online services. Customer service officers are also on hand to help these users who need guidance.

With the proliferation of mobile phones and devices among the population, delivering mobile Government services has become a key imperative for the public sector. Under the Mobile Government (m-government) project by the Ministry of Finance and the IDA, there are currently some 200 Government services that can be conveniently accessed through mobile devices. These include Central Provident Fund account enquiries, Certificate of Employment, results and updates on traffic conditions.

The m-Government project involves 15 ministries, nine organs of state and more than 60 statutory boards, and is part of the Government IT Masterplan, iGov2010. Some examples of innovative m-services that have benefited a broad spectrum of the public include the following:

- Police SMS 70999 hotline service. Members of the hearing and speech impaired community can 
now send emergency text messages to a new SMS helpline - SMS 70999. The service was introduced by the Singapore Police Force and National Council of Social Service to serve the needs of the hearing and speech-impaired community, which is estimated to number about 10,000.

- Singapore Government Directory Interactive (SGDI) SMS: Mobile phone users can conveniently obtain the contact information of government officers - indicated on the SGDI website - via SMS. Users need only send an SMS to 74588 (or key SGOVT) and follow the necessary steps to obtain the contact information they need.

- SLS StreetMap Mobile: Users of compatible PDAs, PDA phones and smartphones can searach the location maps of the Singapore Land Authority (SLA) StreetMap@ Singapore electronic street directory. The utility software can be downloaded for free, and runs on mobile devices that run on Windows Mobile Operating System. Launched by the SLA and MapKing (Singapore), StreetMap Mobile contains some 2,000 buildings, 4200 named roads, and some 120,000 updated address points.

Simplifying business-government interactions with UEN: SAY goodbye to multiple identification num- bers issued by different government agencies. From January 1, 2009, all Singapore-registered entities such as businesses, societies, healthcare institutions and trade unions will be issued a Unique Entity Number (UEN). This will be the unique identifier for these entities, in the same way the NRIC acts as a unique identifier for each Singapore citizen.

The UEN, which is another initiative under the iGov2010 Masterplan, will enable the various entities to enjoy the convenience of a single identification number when interacting with all Government agencies.

For businesses, the UEN will help to expedite processes such as the filing of corporate tax returns, applications for import and export permits, and submission of employees' CPF contributions.

Mr. Teng Theng Dar, Chief Executive Officer of the Singapore Business Federation (SBF) said, "We welcome and support the introduction of UEN as the only identification number that companies need for interactions between businesses and government agencies. The UEN will simplify and reduce possible errors caused by the use of multiple numbers, thus speeding up transactions. This initiative will enable companies to manage their time more productively, and to them, time is money." 